\title{
MEĐUJEZIČKI UTICAJ U PISANOJ PRODUKCIJI NA ITALIJANSKOM KOD SRBOFONIH UČENIKA ${ }^{1}$
}

\begin{abstract}
APSTRAKT: Rad se zasniva na teorijama o međujezičkom uticaju kako bi se ispitale sledeće varijable: 1) nivo znanja engleskog jezika i 2) uticaj količine izloženosti engleskom jeziku na pojavu međujezičkog uticaja u kontekstu formalnog obrazovanja u Srbiji. U radu se analiziraju rezultati pisane produkcije na italijanskom kao drugom stranom jeziku u cilju oslikavanja oblika međujezika učenika na polju leksike i morfologije. Istraživanje je sprovedeno u Osnovnoj školi „Petar Petrović Njegoš” i obuhvatilo je učenike petog i sedmog razreda koji uče engleski jezik od prvog i italijanski jezik od petog razreda. Pregledom i analizom rezultata istraživanja utvrđeno je da dve vrste međujezičkog uticaja dominiraju prilikom građenja ciljnih reči u pisanoj produkciji na italijanskom jeziku (leksički i morfološki međujezički uticaj), kao i da je međujezički uticaj veći sa višim nivoom znanja.
\end{abstract}

Ključne reči: međujezički uticaj, nivo znanja, količina izloženosti, leksika, morfologija, pisana produkcija, engleski kao prvi strani jezik, italijanski kao drugi strani jezik.

\section{CROSS-LINGUISTIC INFLUENCE IN THE WRITTEN PRODUCTION OF SERBOPHONE STUDENTS IN ITALIAN}

ABSTRACT: The paper is based on the theories of cross-linguistic influence in order to examine the following factors: 1) language proficiency of the English language and 2) influence of amount of exposure to the English language with regard to the cross-linguistic influence. The paper analyzes the results of the written production in Italian in order to define the forms of interlanguage in the field of lexis and morphology. The research was carried out in the primary school „Petar Petrović Njegoš" in Belgrade and includes the fifth and seventh grade pupils studying the English language from the first grade and the Italian language from the fifth grade. By analyzing the results of the research, we discovered that two types of cross-linguistic influence are dominant in the construction of target words (lexical and morphological crosslinguistic influence), as well as that the higher the language proficiency, the greater the crosslinguistic influence is.

Key words: cross-linguistic influence, language proficiency, amount of exposure, lexis, morphology, written production, English as the first foreign language, Italian as the second foreign language.

\footnotetext{
${ }^{1} \mathrm{Rad}$ je zasnovan na doktorskoj disertaciji Detar Jevđović, S. (2018). „Uticaj engleskog jezika na pisanu produkciju na italijanskom kod srbofonih učenika" pod mentorstvom prof. dr Julijane Vučo, Filološki fakultet Univerziteta u Beogradu.
} 


\section{UVOD}

Predmet ovog rada jeste ispitivanje međujezičkog uticaja kao jedne od specifičnosti učenja drugog stranog jezika koja nastaje kao posledica sličnosti i razlika između ciljnog jezika i bilo kod drugog jezika koji je učenik prethodno učio ili istovremeno uči. Budući da se međujezički uticaj najlakše uočava na polju leksike i morfologije (De Angelis 2007), u radu će posebno biti izdvojeni oblici međujezika koji se u tom domenu javljaju. Uz osvrt na uticaj varijabli - nivo znanja engleskog jezika i količina izloženosti engleskom jeziku - u fokusu rada nalazi se istraživanje koje obuhvata kritičku analizu leksičkih i morfoloških konstrukcija međujezika kod učenika petog i sedmog razreda. Cilj istraživanja usmeren je na utvrđivanje činjenice da li engleski jezik ima veći uticaj na polju leksike i morfologije u italijanskom kao drugom stranom jeziku kod onih ispitanika koji poseduju viši nivo znanja engleskog jezika i koji su u većoj meri bili njemu izloženi. U istraživanju se pošlo od pretpostavke da međujezički uticaj engleskog kao prvog u produkciji italijanskog kao drugog stranog jezika zavisi od varijabli nivoa znanja i količine izloženosti, kao i da je međujezički uticaj veći na polju leksike i morfologije sa višim nivoom znanja. Ovaj segment istraživanja zasniva se na studiji (Williams and Hammarberg 1998) koja ističe da se sa povećanjem nivoa znanja i količinom izloženosti prvom stranom jeziku povećava i učestalost međujezičkog uticaja iz prvog stranog jezika.

Prvi deo rada obuhvata teorijski okvir koji iz više uglova sagledava pojavu međujezičkog uticaja. Pored definisanja samog pojma, opisane su i varijable nivoa znanja i količine izloženosti, kao i odlike i oblici međujezika koji se tom prilikom javljaju.

U drugom delu rada izneti su i analizirani rezultati istraživanja pisane produkcije na italijanskom jeziku učenika petog i sedmog razreda. Cilj analize ovog dela istraživanja jeste izdvajanje i određivanje konstrukcija karakterističnih za međujezik učenika na polju leksike i morfologije, kao i utvrđivanje činjenice da li engleski jezik ima veći uticaj na polju leksike i morfologije onih ispitanika koji poseduju viši nivo znanja engleskog jezika i koji su u većoj meri bili njemu izloženi. Osim toga, ovaj deo rada obuhvata i poređenje rezultata učenika petog i sedmog razreda.

Zaključak rada posvećen je analizi istraživanja koje je sagledano u okviru postavljenih ciljeva i hipoteza. 


\section{MEĐUJEZIČKI UTICAJ}

Studije o međujezičkom uticaju (eng. crosslinguistic influence) nastoje da objasne kako i pod kojim uslovima prethodno jezičko znanje utiče na produkciju, razumevanje i razvoj ciljnog jezika. S tim u vezi javljaju se i razmimoilaženja u terminologiji koja se koristi pri imenovanju ove pojave (Weinreich 1953). Odlin (1989: 27) definiše međujezički transfer kao uticaj koji je rezultat sličnosti i razlika između ciljnog jezika i drugog prethodno učenog jezika.

\section{FAKTORI KOJI UTIČU NA POJAVU MEĐUJEZIČKOG UTICAJA}

Proučavanjem međujezičkog uticaja identifikovano je više faktora koji utiču na količinu učenikovog oslanjanja na prethodno naučene jezike i određuju tip međujezičkog uticaja na ciljni jezik. Istraživanja u ovoj oblasti (Williams and Hammarberg 1998; De Angelis and Selinker 2001; Cenoz 2001; Ringbom 2001; Hammarberg 2001; Dewaele 2001; Tremblay 2006) kao najraspostranjenije faktore ove pojave ističu: tipološku bliskost, nivo znanja, količinu izloženosti, upotrebu jezika, tj. učestalost korišćenja, redosled usvajanja, status jezika i kontekst. Kada govorimo o faktoru bliskosti jezika, rana istraživanja (Ringbom 1987) navode da, ukoliko su jezici koji se uče tipološki slični, onda postoje olakšavajući faktori prilikom učenja (pozitivan transfer). Međutim, kada postoji divergencija između jezika, do međujezičkog uticaja može doći u obliku grešaka, preterane ili, sa druge strane, nedovoljne produkcije, kao i pogrešnog razumevanja iliti negativnog transfera (Odlin 1989).

\subsection{Nivo znanja}

U vezi sa faktorom nivo znanja jezika, Ringbom (1986) ističe da što je znanje ciljnog jezika niže, učenik je više prisiljen da se osloni na druga prethodna znanja koja poseduje. Taj drugi jezik podrazumeva sve strane jezike koje je polaznik prethodno učio, a obuhvata i uticaj maternjeg jezika. Međutim, da bi prvi strani jezik pružio materijal za međujezički uticaj, govornik mora posedovati određeni nivo znanja prvog stranog jezika (Hammarberg 2001).

U vezi sa međujezičkim uticajem u okviru učenja drugog stranog jezika, Ringbom (1987) primećuje da nivo znanja izvornog jezika određuje tip transfera u ciljnom jeziku. U prvim svojim radovima (Ringbom 1986, 1987) zastupa ideju da 
je transfer oblika ${ }^{2}$ relativno površan tip međujezičkog uticaja. Navodi da se on podjednako tiče i maternjeg i prvog stranog jezika budući da nivo znanja ne utiče na pojavu ovog tipa međujezičkog uticaja. Međutim, kada govori o transferu značenja Ringbom smatra da do njega može doći samo sa jezika koje govornik dobro poznaje, odnosno sa maternjeg ili prvog stranog jezika kojima govornik dobro vlada što se vidi u fluentnosti izražavanja (De Angelis 2007). U kasnijim radovima Ringbom (2001) zastupa tezu da prvi strani jezik pruža više materijala za transfer oblika.

\subsection{Količina izloženosti}

U literaturi koja se bavi međujezičkim uticajem pojedini autori (Odlin 1989; Murphy 2003) smatraju da faktor količine izloženosti ima jak uticaj na verovatnoću pojave kako pozitivnog tako i negativnog transfera. Murphy (2003: 8) definiše ovu varijablu kao dužinu boravka u sredini ciljnog jezika ili, u slučaju učenika stranog jezika, kao količinu stranog jezika kojoj je učenik izložen u školskom ili vanškolskom ambijentu.

\section{OBLICI MEĐUJEZIČKOG UTICAJA}

\subsection{Leksički međujezički uticaj}

U jednoj od svojih najopsežnijih studija iz 1987. godine Ringbom je izdvojio nekoliko oblika međujezičkog uticaja stranog jezika koje je uopšteno kategorizovao kao pozajmljenice (u koje uključuje hibridne tvorevine i složenice) i oblike leksičkog međujezičkog uticaja (kalkovi, semantičke ekstenzije, kognati i lažni prijatelji).

Ringbom (1987: 117) je još ranije u svom radu ukazao i na razlike između kognata i lažnih prijatelja, navodeći da prvi označavaju reči istog korena i uglavnom istog značenja, dok se drugi odnose na reči istog korena, ali drugačijeg značenja.

\footnotetext{
${ }^{2}$ Ringbom $(1987,2001)$ pravi razliku između transfera oblika i značenja. Pod transferom oblika Ringbom podrazumeva prebacivanje s jednog jezika na drugi (preključivanje koda), hibridne tvorevine, slivenice i varljive kognate, dok transfer značenja uključuje kalkove i semantičke ekstenzije (v. Odeljak 4.1. Leksički međujezički uticaj).
} 
Na gorenavedenu klasifikaciju poziva se i autorka De Angelis (2007) i u skladu sa njom daje primere leksičkog međujezičkog uticaja, izdvaja i definiše sledeće oblike međujezika:

1. Kalkovi - slučaj kada se semantička svojstva jedne reči prenose na kombinaciju leksičkih jedinica. Na primer: 'child wagon' za 'pram' (na švedskom barnvagn);

2. Semantičke ekstenzije - slučaj kada se semantička svojstva proširuju na reč iz prvog stranog jezika. Na primer: 'He bit himself in the language' (na finskom kieli $=$ znači i 'tongue' i 'language');

3. Kognati (uključuju i lažne prijatelje) - slučajevi formalne međujezičke sličnosti reči različitih odnosa:

a) u potpunosti različito značenje: 'At the time he works in a fabric' (na švedskom fabric $=$ 'factory');

b) slično, ali identično značenje van konteksta: 'The next day we grounded a club' (na švedskom grunda = 'found');

c) u nekim, ali ne svim kontekstima identično ili skoro identično značenje:

'The hound is the best friend of man' (na švedskom hund = 'dog', povremeno isto 'hound');

4. Hibridne tvorevine i slivenice - slučajevi morfološke ili fonetske modifikacije reči u skladu sa normama prvog stranog jezika. Na primer: 'In the morning I was tired and in the evening I was piggy' (na švedskom pigg = 'refreshed');

5. Pozajmljenice - slučajevi potpune zamene jezika ili releksifikacije ${ }^{3}$, tj. izostanka modifikacije reči u skladu sa normama prvog stranog jezika. $\mathrm{Na}$ primer: 'I'm usually very pigg after the diet' (na švedskom pigg = 'refreshed').

\subsection{Morfološki transfer}

Pregledom literature koja se bavi međujezičkim uticajem nailazi se na istraživanja koja ističu da je transfer vezanih morfema, iako moguć, redak u toku učenja prvog stranog jezika (Weinreich 1953; De Angelis 2007). Međutim, po

\footnotetext{
${ }^{3}$ Releksifikacija je zamena domaće reči ili izraza stranim. U ovom slučaju se radi o zameni reči drugog stranog jezika originalnom rečju ili izrazom iz prvog stranog jezika.
} 
mišljenju nekih autora (Murphy 2003) on predstavlja bitnu karakteristiku leksičkog međujezičkog uticaja u toku produkcije drugog stranog jezika.

Pojedini autori (De Angelis and Selinker 2001: 43) takođe nude primere morfološkog međujezičkog uticaja navodeći slučajeve u kojima slobodna ili vezana morfema maternjeg ili prvog stranog jezika u kombinaciji sa drugom slobodnom ili vezanom morfemom iz ciljnog jezika formira približnu ciljnu reč.

\section{ISTRAŽIVANJE}

Istraživanje je sprovedno pri kraju drugog polugodišta školske 2014/15. godine u Osnovnoj školi „Petar Petrović Njegoš” u Beogradu. Učestvovalo je 86 učenika petog i sedmog razreda i dva nastavnika, od kojih je jedan držao nastavu engleskog jezika, a drugi nastavu italijanskog jezika u pomenutim razredima.

Učenici koji su učestvovali u istraživanju bili su raspoređeni u dve osnovne grupe: (A) učenike petog razreda sa 43 ispitanika i (B) učenike sedmog razreda sa takođe 43 ispitanika. Svim učenicima je maternji jezik srpski, prvi strani jezik engleski, a drugi strani italijanski. Engleski jezik uče od prvog, dok italijanski jezik uče od petog razreda.

\subsection{Metode, tehnike i instrumenti istraživanja}

U okviru istraživanja primenjena je kombinovana metoda koja obuhvata primenu kvalitativne i kvantitativne metode. Kada je reč o sagledavanju konteksta nastave engleskog jezika (struktura časova, upotreba jezika u učionici, nastavne metode i nastavni materijal) upotrebljena je kvalitativna metoda, dok je za poređenje $\mathrm{i}$ analizu rezultata anketiranja $\mathrm{i}$ testiranja ispitanika primenjena kvantitativna metoda.

Od tehnika rada primenjeno je anketiranje predmetnih nastavnika i učenika, kao i testiranje učenika u vezi sa predmetom istraživanja.

Kao instrumenti istraživanja upotrebljeni su upitnici za anketiranje nastavnika i učenika i testovi za proveru nivoa znanja engleskog jezika, kao i testovi za proveru pisane produkcije italijanskog jezika.

Upitnici za nastavnika sadrže, pored ličnih podataka (ime i prezime, godine radnog staža, nivo znanja jezika koji predaje, kao i ostalih jezika koje poznaje) i podatke u vezi sa fondom časova predmeta koji predaje, strukturom časova, nastavnim metodama i sredstvima koje koristi u nastavi, upotrebom stranog i maternjeg jezika u nastavi, kao i kriterijumima pri ocenjivanju učenika. Upitnik za učenike sadrži uvodne napomene i sledeće informacije: lične podatke (pol, razred, 
maternji jezik učenika i roditelja, stručna sprema roditelja, poznavanje drugih stranih jezika), jezičko iskustvo ispitanika (kontekst učenja, izloženost, upotreba i učestalost korišćenja engleskog jezika u školi i van nje), kao i ocenu iz engleskog jezika na poslednjem polugodištu.

Testovi za proveru nivoa znanja engleskog jezika sačinjeni su na osnovu tematskog sadržaja udžbenika koji se koriste u nastavi (Project 2 i Project 4). U testu za peti razred iz engleskog jezika zastupljene su sledeće tehnike: dopuna rečenica rečju koja nedostaje, dopuna rečenica jednom od ponuđenih reči iz zagrade, povezivanje reči sa leve i desne strane, upotreba odgovarajućeg oblika reči iz zagrade, dopuna rečenica sa ponuđenim odgovorima, provera razumevanja teksta pitanjima sa višestrukim izborom (tri distraktora), kao i pisanje kratkog sastava na zadatu temu. Slične tehnike korišćene su i u testu za sedmi razred iz engleskog jezika: upotreba odgovarajućeg oblika reči iz zagrade, dopuna rečenica rečju koja nedostaje, dopuna rečenica sa ponuđenim odgovorima, dopuna rečenica jednom od ponuđenih reči iz zagrade, popunjavanje tabele odgovarajućom kategorijom reči, povezivanje reči sa leve i desne strane, provera razumevanja rečenica pitanjima true/false/doesn't it say, kao i pisanje kratkog sastava na zadatu temu. Razlog za odabir ovakvih aktivnosti nalazi se u nameri da se koristi objektivni instrument za određivanje jezičkog nivoa učenika. Za svaki tačan odgovor predviđeno je pozitivno bodovanje. Zadaci su različite težine kako bi se iskristalisali nivoi znanja u vidu brojčanog ocenjivanja. Namera je bila da se na osnovu dobijenih rezultata ustanovi naknadna podela ispitanika na podgrupe: onih sa višim nivoom znanja (ocenjeni sa 5 i 4) i onih sa nižim nivoom znanja (ocenjeni sa 2 i 3). Istraživanje ne uključuje kategoriju nedovoljnog znanja.

Za testiranje pisane produkcije italijanskog kao drugog stranog jezika za peti i sedmi razred korišćene su dve vrste testa. Obim reči u testovima je isti kod obe grupe ispitanika i iznosi oko 60 reči. Prvi test se zasniva na opisu slike (za svaki razred po jedna slika) i uključuje poznatu leksiku i strukture rađene na časovima engleskog i italijanskog jezika. Drugi test podrazumeva pisanje kratkog sastava (sastav je vođen, a instrukcije su date na maternjem jeziku, piše se o temi o kojoj je već bilo reči na časovima engleskog i italijanskog jezika). Namera je bila da se, na osnovu analize grešaka koju učenici prave, prouče oblici transfera u okviru leksike i morfologije, tj. da se izdvoje i izbroje konstrukcije međujezika.

\subsection{Podela ispitanika na podgrupe}

Obrađeni upitnici i ankete pružili su opšti uvid u sliku vezanu za nivo znanja i količinu izloženosti engleskom jeziku ispitanika petog i sedmog razreda. 
Podaci vezani za nivo znanja engleskog jezika utvrđeni su prikupljanjem ocena ispitanika, izvođenjem srednje prosečne ocene, kao i analizom testova za proveru nivoa znanja engleskog jezika. Izvođenjem zaključne ocene iz engleskog jezika učenika petog razreda na polugodištu 2014/15. uočava se da je njih $86 \%$ postiglo odličan i vrlo dobar uspeh, dok je 14\% postiglo dobar i dovoljan uspeh. Analizom zaključnih ocena u sedmom razredu primećuje se da je $79 \%$ učenika postiglo odličan i vrlo dobar uspeh, a njih $21 \%$ dobar i dovoljan. S druge strane, rezultati testiranja učenika iz engleskog jezika u drugom polugodištu školske 2014/15. nedvosmisleno pokazuju da je $72 \%$ učenika petog razreda postiglo odličan i vrlo dobar uspeh, a njih $28 \%$ dobar i dovoljan. Rezultati učenika sedmog razreda potvrđuju da je njih $81 \%$ postiglo odličan i vrlo dobar uspeh iz engleskog jezika, dok je njih 19\% postiglo dobar i dovoljan. Na osnovu navedenih podataka, poređenjem uspeha učenika na testovima sa zaključnim ocenama sa polugodišta 2014/15. godine i izvođenjem aritmetičke sredine primećuje se da 79\% ispitanika petog razreda poseduje viši nivo znanja engleskog jezika (ocene 4 i 5), dok njih $21 \%$ pokazuje niži nivo (ocene 2 i 3 ). Istim postupkom se, takođe, dolazi se do zaključka da $80 \%$ ispitanika sedmog razreda iz engleskog jezika poseduje viši nivo znanja (ocene 4 i 5), dok 20\% pokazuje niži nivo znanja (ocene 2 i 3). Niko od ispitanika ne pokazuje nedovoljno stečeno znanje.

Podaci vezani za količinu izloženosti engleskom jeziku utvrđeni su obuhvatanjem nastavnog i vannastavnog inputa. Nastavni input čini celokupan materijal koji je korišćen u nastavi engleskog jezika: udžbenički komplet (Project 2 u petom i Project 4 u sedmom razredu), kao i dodatni materijal koji donosi predmetni nastavnik (slike, fleš karte, posteri, dodatna vežbanja iz stranih udžbenika, tekstovi stranih popularnih pesama, projekti). Vannastavni input uključuje one sadržaje kojima su ispitanici bili izloženi izvan nastavnog okruženja. Obradom ovog dela upitnika saznajemo da pri učenju engleskog jezika svi učenici petog razreda koriste udžbenik, video- zapise (filmove, serije, klipove) - 65,1\%, dodatni materijal koji im donosi predmetni nastavnik (30,2\%), rečnik $(32,6 \%)$, pisma i razglednice $(4,7 \%)$, autentične materijale (brošure, reklame, meni...) $16,3 \%$, audio CD (34,9\%), kompjuter/CD-ROM (41,9\%), časopise, novine, knjige i stripove $(37,2 \%)$, poeziju, priče i bajke $(16,3 \%)$, pesme i recitacije $(34,9 \%)$, igrice $(58,1 \%)$. Pri učenju engleskog jezika svi učenici sedmog razreda koriste udžbenik, video-zapise (filmove, serije, klipove) - 60,5\%, dodatni materijal koji im donosi predmetni nastavnik $(20,9 \%)$, rečnik $(23,3 \%)$, pisma i razglednice $(11,6 \%)$, autentične materijale (brošure, reklame, meni...) - 14\%, audio-CD $(32,6 \%)$, kompjuter/CD-ROM (55,8\%), časopise, novine, knjige i stripove $(34,9 \%)$, poeziju, 
priče i bajke $(9,3 \%)$, pesme i recitacije $(34,9 \%)$, igrice $(60,5 \%)$. Imajući u vidu iznete podatke, došlo se do zaključka da je 39,5\% ispitanika petog razreda u velikoj meri izloženo engleskom jeziku, a njih $60,5 \%$ u manjoj meri. Kod ispitanika sedmog razreda situacija je donekle drugačija: $46,5 \%$ ispitanika je u velikoj meri izloženo engleskom jeziku, a 53,5\% u manjoj meri.

Detaljan uvid i analiza podataka dobijenih upitnikom za učenike, kao i testovima nivoa znanja engleskog jezika omogućili su dodatnu podelu ispitanika na podgrupe.

U skladu sa navedenim podacima, u okviru svakog razreda možemo razlikovati sledeće podgrupe:

I Visok nivo znanja / velika količina izloženosti

II Visok nivo znanja / mala količina izloženosti

III Nizak nivo znanja / mala količina izloženosti.

Na osnovu dalje analize dobijenih podataka iz upitnika za učenike i testova nivoa znanja engleskog jezika dolazi se do zaključka da se $39 \%$ ispitanika petog razreda (17 ispitanika) može svrstati u I podgrupu, 35\% ispitanika (15 učenika) u II, a $26 \%$ ispitanika (11 ispitanika) u III podgrupu. Ukoliko se pogleda situacija u sedmom razredu, uočava se da $47 \%$ ispitanika (20 učenika) spada u I podgrupu, $30 \%$ ispitanika (13 učenika) u II, dok je 23\% (10 učenika) onih koji spadaju u III podgrupu.

\subsection{Rezultati pisane produkcije na italijanskom jeziku učenika petog i sedmog razreda}

Rezultati pisane produkcije na italijanskom jeziku učenika petog i sedmog razreda pokazali su da sve tri grupe (Visok nivo znanja / velika količina izloženosti, Visok nivo znanja / mala količina izloženosti i Nizak nivo znanja / mala količina izloženosti) prave leksičke i morfološke greške uslovljene međujezičkim uticajem iz engleskog jezika.

$\mathrm{Na}$ osnovu klasifikacije konstrukcija međujezika koju daje De Angelis (2007: 42) kod učenika petog i sedmog razreda mogu se izdvojiti sledeći oblici međujezičkog uticaja: kalkovi, semantičke ekstenzije, kognati, hibridne tvorevine i slivenice, kao i pozajmljenice (v. Tabelu 1).

Kod prve grupe učenika petog razreda (Visok nivo znanja / velika količina izloženosti) zabeleženi su sledeći primeri kalkova: sport borsa, al uno place, tennis racheta. Kod druge grupe (Visok nivo znanja / mala količina izloženosti) i treće grupe učenika petog razreda (Nizak nivo znanja / mala količina izloženosti) nisu zapaženi oblici kalkova. 
Kod prve grupe ispitanika sedmog razreda (Visok nivo znanja / velika količina izloženosti), zabeleženi su sledeći primeri kalkova: photo macchina, ariaplane, ariaporto. Kod druge (Visok nivo znanja / mala količina izloženosti) i treće grupe učenika sedmog razreda (Nizak nivo znanja / mala količina izloženosti) nisu zapaženi oblici kalkova.

Ukoliko se pogledaju oblici semantičkih ekstenzija, kod prve grupe učenika petog razreda (Visok nivo znanja / velika količina izloženosti) nailazi se na primere neodgovarajuće lične zamenice u konstrukcijama sa glagolom piacere (io piace... ili čak Lei non piacciono). Kada je reč o semantičkim ekstenzijama kod druge grupe učenika petog razreda (Visok nivo znanja / mala količina izloženosti), zabeležen je samo jedan primer: io sono undici. Kod treće grupe učenika petog razreda (Nizak nivo znanja / mala količina izloženosti) nisu zapaženi oblici semantičkih ekstenzija.

Ukoliko se pogledaju oblici semantičkih ekstenzija kod prve grupe ispitanika sedmog razreda (Visok nivo znanja / velika količina izloženosti), nailazi se na primere neodgovarajuće upotrebe imenica ili neodgovarajuće lične zamenice $\mathrm{u}$ konstrukcijama sa glagolom piacere (organizzazione ili čak organizazione/organizatione, foresta, lei piace stare nel parco). U pogledu semantičkih ekstenzija kod druge grupe učenika sedmog razreda (Visok nivo znanja / mala količina izloženosti) izdvajaju se primeri upotrebe neodgovarajuće imenice kao i lične zamenice u konstrukcijama sa glagolom piacere (io piace la statua di Michelangelo, organizazione). Kod treće grupe učenika sedmog razreda (Nizak nivo znanja / mala količina izloženosti) nisu zapaženi oblici semantičkih ekstenzija.

Kada su u pitanju kognati kod prve grupe učenika petog razreda (Visok nivo znanja / velika količina izloženosti) nailazi se na sledeće primere: $i$ miei parenti sono Maria e Milan, takođe i Mio padre e mia madre sono i miei parenti, in inverno nevica e fa molto caldo, Babbo Natale porta $i$ presenti ai bambini, il dono, io resto in casa, classe di italiano. Kada je reč o kognatima kod druge grupe učenika petog razreda (Visok nivo znanja / mala količina izloženosti) beleže se sledeći primeri: presento, Babbo Natale porta i presenti ai bambini, in inverno nevica e fa molto caldo. Kod treće grupe učenika petog razreda (Nizak nivo znanja / mala količina izloženosti) nisu zapaženi oblici kognata.

Kada je reč o kognatima kod prve grupe ispitanika sedmog razreda (Visok nivo znanja / velika količina izloženosti) nailazi se na sledeće primere: sono andato a Firenze con $i$ miei parenti, molti monumenti popolari ili populari, mobile, presente ili presento, caldo ili coldo, camera, rumore, nella città non ci sono 
fattorie, i momenti che io spendevo con la famiglia, a lei piace come spende il tempo, lei resta nel parco, commerciali. Kada su u pitanju kognati kod druge grupe učenika sedmog razreda (Visok nivo znanja / mala količina izloženosti) zapažaju se sledeći primeri: ci stendiamo, camera, ho comprato un presente bellissimo, presento, caldo, populare ili čak popularo, con i miei parenti. Kada je reč o kognatima kod treće grupe učenika sedmog razreda (Nizak nivo znanja / mala količina izloženosti) izdavajaju se samo tri primera (populare, coldo, presenti da donne).

Kod prve grupe učenika petog razreda (Visok nivo znanja / velika količina izloženosti) nailazi se na mnoštvo primera oblika hibridnih tvorevina i slivenica, a među njima najviše onih konstrukcija kod kojih se na reč iz engleskog jezika dodaje morfema za građenje muškog ili ženskog oblika, kao i oblika množine reči u italijanskom jeziku, zatim odgovarajućeg lica prezenta, kao i reči napisanih pod uticajem fonetskih pravila engleskog jezika (guitaro, computero e radio, lampo, magazini, sponga, umbrello, syropo, palaca, palaco, collectia, colectione, testo, ospidal ili čak ospidale, corridoro, fooda, io vado tu guardare i negozi / Io vado tu scuola di disegno, loro tokano, schuola, geographia). Kada su u pitanju hibridne tvorevine i slivenice kod druge grupe učenika petog razreda (Visok nivo znanja / mala količina izloženosti) beleži se dosta primera reči engleskog jezika kod kojih se dodaje italijanska morfema za građenje oblika muškog ili ženskog roda; zatim reči napisanih pod uticajem fonetskih pravila engleskog jezika (computero, lampo, io ho tou fratelli, restaurante, ballo è di fronte a bed, septembro ili septembre, scholla ili čak schuola, umbrello, cantante perfecto, apartmento, colectione, hospedale, doro, lei è smarta, thre). Kada je reč o hibridnim tvorevinama i slivenicama kod treće grupe učenika petog razreda (Nizak nivo znanja / mala količina izloženosti) uočavaju se primeri kod kojih se dodaje italijanska morfema za građenje oblika muškog ili ženskog roda; zatim reči napisanih pod uticajem fonetskih pravila engleskog jezika (lampo, beggo, computero ili čak computere, commodo, umbrelo ili čak umbrello, vollibolle, schula ili čak scholo, augosto, choccolato, pencilo).

Među oblicima hibridnih tvorevina i slivenica kod prve grupe ispitanika sedmog razreda (Visok nivo znanja / velika količina izloženosti) najviše se uočavaju oni primeri kod kojih se na reč iz engleskog jezika dodaje morfema za građenje muškog ili ženskog oblika, kao i oblika množine reči u italijanskom jeziku; zatim morfeme za građenje oblika prezenta glagola, imenica koje označavaju mesto gde se nešto obavlja, kao i reči napisanih pod uticajem fonetskih pravila engleskog jezika (tre ragazzi che rajdano la bicicletta, restaurante, baloone ili čak ballone/balone, placi verdi, dopo siamo returno, traditionale, traditione, la macchina di photographia, čak $i$ photographica, pullovero, patienti, tropheo ili trophei, vinjardo, populare, populara, 
titla, appointamento, februario, reservatione ili reservazione, caffeteria ili cafeteria, pochetti, schuola, il suo cane favorito, e poi rimembro). Kada je reč o hibridnim tvorevinama i slivenicama kod druge grupe učenika sedmog razreda (Visok nivo znanja / mala količina izloženosti) moguće je izdvojiti one oblike koji su napisani pod uticajem fonetskih pravila engleskog jezika, zatim one nastale dodavanjem morfeme za građenje oblika infinitiva ili trećeg lica jednine prezenta, kao i morfema za građenje muškog ili ženskog oblika, kao i oblika množine reči u italijanskom jeziku (cathedrale, photographia, photographica, un uomo sellare i balloni, un uomo che solde, parko, capa, sporti, tropheo, controle, reservazione, ragazzi rajdare la bicicletta, pullovero, populare, titlo, appointamento). Kod treće grupe učenika sedmog razreda (Nizak nivo znanja / mala količina izloženosti) mogu se uočiti oblici hibridnih tvorevina i slivenica, među kojima se izdvajaju najviše one konstrukcije kod kojih se na reč iz engleskog jezika dodaje morfema za građenje muškog ili ženskog oblika, kao i oblika množine reči u italijanskom jeziku, zatim reči napisanih pod uticajem fonetskih pravila engleskog jezika (balloone ili čak balloono/balloni/ballooni, parko, centero, cappo, pullovero, restaurante, reservazione, sporti, victoria, titlo, theatro, actore, doctore).

I među oblicima pozajmljenica kod prve grupe učenika petog razreda (Visok nivo znanja / velika količina izloženosti) nailazi se na veliki broj primera, naročito na upotrebu odgovarajućih predloga karakterističnih za engleski jezik ili reči napisane u originalu kao u engleskom jeziku. Zanimljiva je i upotreba lične zamenice $I$, nastavka 's za građenje saksonskog genitiva, kao i upotreba trećeg lica jednine glagola to be (on letto, on scrivania, andiamo to cinema, festeggio il mio compleanno on ventidue gennaio, umbrella, sandwich, design, from Belgrado, voglio to guardare, decidono to entrano, quando voglio to compro, biglietto for cinema, I mi alzo, I gioco ai videogiochi, I mangio alle 12, I arrivo, I ho, lui's zaino, lo sport on TV, film is tradizionale, una volta at mese, parlo on inglese e italiano, palla è di front of letto, la capital dell'Italia). Kada je reč o pozajmljenicama kod druge grupe učenika petog razreda (Visok nivo znanja / mala količina izloženosti) beleže se primeri upotrebe engleskih reči napisanih u originalu. Naročito je česta upotreba engleskih predloga. Zanimljiva je i upotreba lične zamenice $I$ i $M e$, kao i zamenice u kombinaciji sa trećim licem jednine glagola to be: It's (in letto, on the letto, on letto, on scrivania, gioco on computer, racket, vanno to mio compleanno, vado to cinema, regalo to nonni, vado to nonno e nonna, regalo libri o dolci to altri, vai to Via Resavska, in camera è bed, accanto a bed, mio compleanno is of 5 september, sandwich, sopra i letto ci sono molti posters, ski, me non vado allo stadio, it's divertente, I dormo, I guardo la TV, I ho 12 anni). Kada su pozajmljenice u pitanju kod treće grupe učenika petog razreda (Nizak nivo znanja / mala količina izloženosti), takođe se nailazi na primere reči iz engleskog 
jezika napisanih u originalu, kao i na upotrebu nekoliko engleskih predloga i lične zamenice they (on letto, vado to Petar Petrović scuola, ball, posters, tomato, bevo milk, photo, they vivono, ski, preferiti subject).

Mnoštvo je primera pozajmljenica i kod prve grupe ispitanika sedmog razreda (Visok nivo znanja / velika količina izloženosti) nastalih upotrebom engleskih reči napisanih u originalu. Jedan deo leksike odnosi se i na tehnološka dostignuća, pa učenici u tom kontekstu koriste dosta engleskih reči. Zanimljiva je i upotreba engleskih predloga to i on, kao i ličnih zamenica he i we (c'è un ragazzo e una ragazza a fare jogging, restaurant, balloon, hotel, ragazzi giocano, leggi il nostro plan, photo, cathedral, success, poster, violence, show, films, caries, protests, 2 laptops, ha portato vestiti, cd, mp3 player, tablet, he è basso/ he ha capelli corti, we andavo con il treno, non vuole to andare, she say on telefono, on la via). Oblici pozajmljenica kod druge grupe učenika sedmog razreda (Visok nivo znanja / mala količina izloženosti) mahom uključuju reči preuzete direktno iz engleskog jezika i napisane u originalu. Za većinu ovih reči postoji adekvatna reč na italijanskom jeziku koju su učenici obrađivali sa predmetnim nastavnikom. Interesantna je i upotreba lične zamenica he, kao i trećeg lica prezenta glagola to be (ci sono due ragazzi a fare jogging, giocano football, persone sitting, cap, va al shopping, show, success, nelle poster toscane, piece teatrale, protest, reservation, victori, è fanny, he prima va in casa in campagna, he ha noleggiato una macchina, lo sport ideale is). Kada je reč o pozajmljenicama kod treće grupe učenika sedmog razreda (Nizak nivo znanja / mala količina izloženosti) nailazi se, takođe, na primere reči iz engleskog jezika napisane u originalu, kao i upotrebu engleskog glagola to hang, predloga to i with, i veznika but (due persone fanno jogging, vado in center, hotel, restaurant, le persone hanging to cane, basket, show, lui va with suo padre, ascolta la musica but not molto).

\subsection{Uporedna analiza rezultata pisane produkcije učenika petog $i$ sedmog razreda}

Kada je reč o poređenju rezultata učenika petog i sedmog razreda (Tabela 1) zapaža se generalno veći broj međujezičkih konstrukcija nastalih pod uticajem engleskog jezika kod učenika sedmog razreda, što je u skladu sa pretpostavkom da je međujezički uticaj veći na polju leksike i morfologije što je nivo znanja viši (v. Odeljak 5.2.).

Učenici sedmog razreda duže uče engleski jezik, te se, upoređivanjem rezultata testiranja, dobija kompletna slika koja govori u prilog studije (Williams and Hammarberg 1998) - studija ističe da se sa povećanjem nivoa znanja i količinom izloženosti prvom stranom jeziku povećava i učestalost međujezičkog uticaja iz prvog stranog jezika (v. Odeljak 5.2.). 
S druge strane, budući da je najviše oblika međujezika zabeleženo kod ispitanika oba razreda koji poseduju visok nivo znanja i koji su u velikoj meri bili izloženi engleskom jeziku, zaključuje se da varijable nivo znanja i količina izloženosti utiču na pojavu međujezičkog uticaja engleskog u produkciji italijanskog jezika. Takođe, prisustvo međujezičkih konstrukcija kod ispitanika sa niskim nivoom znanja i manjom izloženošću engleskom jeziku, upućuje na zaključak da varijable nivo znanja i izloženost nisu jedine koje utiču na pojavu međujezičkog uticaja na ovom uzrastu.

\begin{tabular}{|c|c|c|c|c|c|c|}
\hline & \multicolumn{3}{|c|}{ Oblici međujezika učenika 5. razreda } & \multicolumn{3}{|c|}{ Oblici međujezika učenika 7. razreda } \\
\hline & $\begin{array}{l}\text { Visok ni } \\
\text { englesk }\end{array}$ & $\begin{array}{l}\text { o znanja } \\
\text { g jezika }\end{array}$ & $\begin{array}{c}\text { Nizak nivo } \\
\text { znanja } \\
\text { engleskog } \\
\text { jezika }\end{array}$ & $\begin{array}{l}\text { Visok ni } \\
\text { engleskc }\end{array}$ & $\begin{array}{l}\text { o znanja } \\
\text { g jezika }\end{array}$ & $\begin{array}{c}\text { Nizak nivo } \\
\text { znanja } \\
\text { engleskog } \\
\text { jezika }\end{array}$ \\
\hline & $\begin{array}{c}\text { Velika } \\
\text { količina } \\
\text { izloženosti } \\
\text { engleskom } \\
\text { jeziku }\end{array}$ & $\begin{array}{l}\text { Mala } \\
\text { količina } \\
\text { izloženosti } \\
\text { engleskom } \\
\text { jeziku }\end{array}$ & $\begin{array}{c}\text { Mala } \\
\text { količina } \\
\text { izloženosti } \\
\text { engleskom } \\
\text { jeziku }\end{array}$ & $\begin{array}{l}\text { Velika } \\
\text { količina } \\
\text { izloženosti } \\
\text { engleskom } \\
\text { jeziku }\end{array}$ & $\begin{array}{c}\text { Mala } \\
\text { količina } \\
\text { izloženosti } \\
\text { engleskom } \\
\text { jeziku }\end{array}$ & $\begin{array}{c}\text { Mala } \\
\text { količina } \\
\text { izloženosti } \\
\text { engleskom } \\
\text { jeziku }\end{array}$ \\
\hline & $\begin{array}{c}\text { Broj } \\
\text { učenika: } 17\end{array}$ & $\begin{array}{c}\text { Broj } \\
\text { učenika: } 15\end{array}$ & $\begin{array}{c}\text { Broj } \\
\text { učenika: } 11\end{array}$ & $\begin{array}{c}\text { Broj } \\
\text { učenika: } 20\end{array}$ & $\begin{array}{c}\text { Broj } \\
\text { učenika: } 13\end{array}$ & $\begin{array}{c}\text { Broj učenika: } \\
10\end{array}$ \\
\hline Kalkovi & 3 & & & 3 & & \\
\hline $\begin{array}{l}\text { Semantičke } \\
\text { ekstenzije }\end{array}$ & 2 & 1 & & 5 & 4 & \\
\hline Kognati & 14 & 6 & & 18 & 12 & 3 \\
\hline $\begin{array}{l}\text { Hibridne } \\
\text { tvorevine i } \\
\text { slivenice }\end{array}$ & 32 & 22 & 14 & 40 & 27 & 19 \\
\hline $\begin{array}{l}\text { Pozajmljeni } \\
\text { ce }\end{array}$ & 26 & 25 & 11 & 41 & 31 & 13 \\
\hline Ukupno & 77 & 54 & 25 & 107 & 74 & 35 \\
\hline
\end{tabular}

Tabela 1. Oblici međujezika učenika petog i sedmog razreda

Osim toga, detaljnijom analizom konstrukcija međujezika učenika petog i sedmog razreda uočava se da se kalkovi javljaju samo kod grupe ispitanika oba razreda koji poseduju visok nivo znanja engleskog jezika i koji su u velikoj meri njemu bili izloženi. Interesantno je da su broj i tip kalkova (sa izuzetkom jednog predloškog izraza kod učenika petog razreda) istovetni u oba razreda, a s obzirom na mali broj oblika ovog tipa međujezika dolazi se do zaključka da ovaj tip međujezičkih konstrukcija nije tipičan za uzrast u okviru koga je obavljeno istraživanje. Nameće se i zaključak da se možda ovaj tip oblika međujezika ne zasniva prvenstveno na uticaju 
prvog stranog jezika (Ringbom 2001). Osim toga, istovetan broj kalkova u petom i sedmom razredu navodi na pomisao da se broj ovog oblika međujezika ne povećava sa uzrastom ispitanika kako to pojedina istraživanja ističu (Gost and Celaya 2005; Celaya 2007; Agustín Llach 2010).

Ukoliko se uporede oblici semantičkih ekstenzija ispitanika oba razreda, zapaža se da se ovaj oblik međujezičkih konstrukcija javlja samo kod učenika koji poseduju visok nivo znanja engleskog jezika bez obzira na količinu izloženosti ili broj godina učenja jezika. Za razliku od petog razreda, za koji su karakteristični primeri neodgovarajuće upotrebe lične zamenice u konstrukcijama sa glagolom piacere, kao i glagola to be, kod učenika sedmog razreda izdvajaju se i primeri upotrebe neodgovarajućih imenica nastalih pod uticajem engleskog jezika. Broj ovog oblika međujezika razlikuje se u odnosu na starosnu dob, te se uočava da su učenici sedmog razreda skloniji ovom obliku međujezičkog uticaja.

Što se oblika kognata oba razreda tiče, zapaža se da se ovaj oblik međujezika javlja samo kod učenika petog razreda koji poseduju visok nivo znanja engleskog jezika, dok se kod učenika sedmog razreda javlja i kod učenika sa niskim nivoom znanja engleskog jezika bez obzira na količinu izloženosti. Budući da je kod ove grupe ispitanika sedmog razreda (Nizak nivo znanja / mala količina izloženosti) mali broj ovakvih primera zaključuje se da nivo znanja ima limitiranu ulogu u pojavi ovog tipa transfera. Ovo zapažanje nije u potpunosti u skladu sa navedenim tvrdnjama Ringboma (2001), koji zastupa mišljenje da kognati kao tip transfera forme mogu nastati nezavisno od nivoa znanja jezika (v. Odeljak 3.1.). Broj ovog tipa međujezičkih konstrukcija učenika sedmog razreda je donekle veći u odnosu na ispitanike petog razreda, dok tip kognata pokazuje slične karakteristike u oba razreda.

Ukoliko se osmotre oblici hibridnih tvorevina i slivenica učenika petog i sedmog razreda, može se zapaziti veliki broj sličnih primera reči engleskog jezika. Za razliku od petog razreda, kod starijih ispitanika uočavaju se i oblici nastali dodavanjem morfeme za građenje oblika infinitiva, kao i imenica koje označavaju mesto gde se nešto obavlja. Broj ovog tipa međujezičkih konstrukcija je donekle veći u sedmom razredu, no budući da se javlja kod svih grupa ispitanika oba razreda može se zaključiti i potvrditi Ringbomova teza (2001) po kojoj hibridne tvorevine i slivenice kao tip transfera forme nastaju prevashodno pod uticajem prvog stranog jezika nezavisno od nivoa znanja.

Najveći broj oblika međujezika učenika petog i sedmog razreda zapaža se u okviru pozajmljenica. Broj pozajmljenica u sedmom razredu je znatno veći u odnosu na peti razred (v. Tabelu 1). Na osnovu opisanih rezultata i svega navedenog, moguće je zaključiti da su učenici sedmog razreda skloniji upotrebi pozajmljenica od učenika 
petog razreda što je veoma neobično budući da italijanski jezik uče skoro tri godine (očekivano je da oni poseduju širi vokabular drugog stranog jezika). Pretpostavlja se da je razlog za to nesigurnost u sopstveno znanje, te stoga zbog nedovoljnog poznavanja reči drugog stranog jezika radije pribegavaju duže učenom prvom stranom jeziku, a sve u cilju održavanja komunikacije (Manchón Ruiz 2001). Istraživanja koja su obavili Vilijams i Hamarberg (Williams and Hammarberg 1998), kao i Celaja (Celaya 2007) ističu da su pozajmljenice kao oblik međujezika karakteristične za učenike na početnom nivou učenja ciljnog jezika i da učestalost njihovog javljanja opada sa porastom nivoa znanja i sa ovladavanjem jezičkim veštinama. $U$ vezi sa tim uočava se da rezultati koji su dobijeni u sprovedenom istraživanju nisu u skladu sa gore pomenutim studijama.

U skladu sa iznetim tumačenjima može se uočiti da se i kod ispitanika sedmog razreda javlja potreba za popunjavanjem praznina u znanju ciljnog jezika i da je tip međujezičkog uticaja koji se tom prilikom javlja negativan. S obzirom da je kod učenika sedmog razreda primetan veći broj oblika međujezika nastalih kao posledica negativnog transfera (pozajmljenice, hibridne tvorevine i slivenice, lažni prijatelji) zaključuje se da ovakvi rezultati nisu u skladu sa pomenutim studijama (Ringbom 1987; Williams and Hammarberg 1998) koje zastupaju mišljenje da se u pisanju učenika početnog nivoa znanja može uočiti mnogo više primera negativnog transfera $u$ odnosu na one sa višim nivoom znanja. S druge strane, veći broj oblika kognata kao primera pozitivnog transfera kod učenika sedmog razreda ukazuje na činjenicu da se ovaj tip međujezika povećava sa znanjem prvog stranog jezika (Odlin 1989). U tom smislu nameće se zaključak da se ne može sa sigurnošću tvrditi da transfer opada kako nivo znanja ciljnog jezika raste, barem dok pojedinac ne dostigne visok nivo znanja ciljnog jezika (De Angelis 2007). Takođe, negativan transfer se može objasniti i činjenicom da učenici na ovom nivou znanja engleskog jezika još uvek nisu dostigli visok nivo automatizacije (Tremblay 2006).

\section{ZAKLJUČAK}

Rezultati sprovedenog testiranja učenika petog i sedmog razreda nam ukazuju na činjenicu da prilikom građenja ciljnih reči u pisanoj produkciji na italijanskom jeziku dominiraju dve vrste međujezičkog uticaja:

1. Leksički međujezički uticaj koji se odnosi na upotrebu cele neciljne reči (iz engleskog jezika) u produkciji ciljne reči (u italijanskom jeziku) i

2. Morfološki međujezički uticaj koji se odnosi na produkciju oblika međujezika kod koga se slobodna ili vezana morfema iz engleskog jezika kombinuje sa 
slobodnom ili vezanom morfemom iz italijanskog jezika u cilju nastajanja reči slične onoj u ciljnom jeziku.

Leksički i morfološki transfer se u najvećoj meri odnose na upotrebu neciljne reči ili morfeme u produkciji ciljnog jezika.

Na kraju se može zaključiti da se na ovom uzrastu (peti i sedmi razred) u velikoj meri javljaju oblici transfera forme (pozajmljenice, hibridne tvorevine i slivenice, kognati), dok se oblici transfera značenja (kalkovi i semantičke ekstenzije) retko ili skoro uopšte ne pojavljuju (v. Tabelu 1). Ovo je u potpunosti u skladu sa onim što i sam Ringbom (2001: 68) zaključuje kada navodi da će, gde god imamo uticaj prvog stranog na drugi strani jezik, to biti transfer celog oblika reči prvog stranog jezika, ili u potpunosti ili u nešto izmenjenom obliku. Rezultati istraživanja ukazuju i na činjenicu da se transfer oblika ne odnosi isključivo i samo na celu reč, kao kod pozajmljenica već u slučaju hibridnih tvorevina i slivenica on uključuje i vezane morfeme (Hammaberg 2001; De Angelis and Selinker 2001; Murphy 2003).

\section{LITERATURA}

Agustín Llach, M. P. (2010). An Overview of Variables Affecting Lexical Transfer in Writing: Review Study. International Journal of Linguistics 2: 1-17.

Celaya, M. L. (2007). I study natus in English': lexical transfer in CLIL and regular learners in Paper presented at the AESLA Conference, Murcia, Spain, April (Murcia: University of Murcia): 19-21.

Cenoz, J. (2001). The effect of linguistic difference, L2 status and age on crosslinguistic influence in third language acquisition, in Cross-linguistic influence in third language acquisition: Psycholinguistic perspectives, eds. J. Cenoz, B. Hufeisen and U. Ulrike (Clevedon: Multilingual Matters): 9-20.

De Angelis, G. and Selinker, L. (2001). Interlanguage transfer and competing linguistic systems in the multilingual mind, in Cross-linguistic influence in third language acquisition: Psycholinguistic perspectives, eds. J. Cenoz, B. Hufeisen and U. Ulrike (Clevedon: Multilingual Matters): 42-58.

De Angelis, G. (2007). Third or Additional Language Acquisition. Clevedon: Multilingual Matters.

Dewaele, J. (2001). Activation or inhibition? The interaction of L1, L2 and L3 on the language mode continuum, in Cross-linguistic influence in third language acquisition: Psycholinguistic perspectives, eds. J. Cenoz, B. Hufeisen and U. Ulrike (Clevedon: Multilingual Matters): 69-89. 
Gost, C., and Celaya, M. L. (2005). Age and the use of L1 in EFL oral production, in Perspectivas Interdisciplinares de la Lingüística Aplicada, eds. M. L. Carrió Pastor (València: Universitat Politècnica de València - AESLA, Asociación Española de Lingüística Aplicada): 129-136.

Hammarberg, B. (2001). Roles of L1 and L2 in L3 production and acquisition, in Cross-linguistic influence in third language acquisition: Psycholinguistic perspectives, eds. J. Cenoz, B. Hufeisen and U. Ulrike (Clevedon: Multilingual Matters): 21-41.

Manchón Ruiz, R. (2001). Un acercamiento psicolingüístico al fenómeno de la transferencia en el aprendizaje y uso de segundas lenguas, in Tendencias y líneas de investigación en adquisición de segundas lenguas, eds. V. Salazar and S. Pastor (Anexo 1: ELUA Estudios de Lingüística de la Universidad de Alicante): $39-71$.

Murphy, S. (2003). Second Language Transfer During Third Language Acquisition. Working Papers in TESOL and Applied Linguistics (Teachers College: Columbia University). 〈https://doi.org/10.7916/D8SF2VN8>

Odlin, T. (1989). Language Transfer. Cross-linguistic Influence in Language Learning. Cambridge: Cambridge University Press.

Ringbom, H. (1986). Crosslinguistic influence and the foreign language learning process. In Crosslinguistic influence in second language acquisition, eds. M. Sharwood Smith and E. Kellerman (Oxford, UK: Pergamon Press): 150-162.

Ringbom, H. (1987). The Role of the First Language in Foreign Language Learning. Clevedon: Multilingual Matters.

Ringbom, H. (2001). Lexical transfer in L3-production. In Cross-linguistic Influence in Third Language Acquisition: Psycholinguistic Perspectives, eds. J. Cenoz, B. Hufeisen and U. Jessner (Clevedon: Multilingual Matters): 59-68.

Tremblay, M. C. (2006). Cross-Linguistic influence in Third Language Acquisition: The role of L2 Proficiency and L2 Exposure. Cahiers Linguistiques d'Ottawa 34: 109-119.

Weinreich, U. (1953). Languages in Contact. Publications of the Linguistic circle of New York 1.

Williams, S. and Hammarberg, B. (1998). Language switches in L3 production: implications for a polyglot speaking model. Applied Linguistics 19 (3): 295333. 
Snežana Z. Detar Jevđović

Primary school „Petar Petrović Njegoš”

\section{CROSS-LINGUISTIC INFLUENCE IN THE WRITTEN PRODUCTION OF SERBOPHONE STUDENTS IN ITALIAN}

\section{Summary}

The subject of the paper is the study of the influence that English as the first foreign language has on the acquisition of Italian as the second foreign language. One of the complex features related to second language acquisition is cross-linguistic influence resulting from similarities and differences between the target language and any other language a learner has previously acquired. Cross-linguistic influence is the most evident in the fields of lexis and morphology defining to a large extent the nature and characteristics of interlanguage occurring on that occasion. The paper is based on the theories of crosslinguistic influence in order to examine the following factors: 1) students' language proficiency in English and 2) influence of the amount of exposure to the English language. The paper analyzes the results of written production in Italian in order to define the forms of interlanguage in the field of lexis and morphology. The research was carried out in one primary school in Belgrade and includes the fifth and seventh grade pupils studying the English language from the first grade and the Italian language from the fifth grade. By examining and analyzing the results of the research, we discovered that two types of crosslinguistic influence are dominant in the construction of target words (lexical and morphological cross-linguistic influence), as well as that the higher the language proficiency, the greater the cross-linguistic influence is.

Key words: cross-linguistic influence, language proficiency, amount of exposure, lexis, morphology, written production, English as the first foreign language, Italian as the second foreign language.

Primljeno: 6. 8. 2020.

Prihvaćeno: 20. 9. 2020. 
